\title{
Developing the Structure of Junior High School Students'Arguments about Ohm's Law
}

\author{
Anastasios Smprinis ${ }^{1}$, Michael Skoumios ${ }^{2 *}$
}

\author{
${ }^{1}$ Hellenic Open University, GREECE \\ 2 Department of Primary Education, School of Humanities, University of the Aegean, GREECE \\ *Corresponding Author: skoumios@rhodes.aegean.gr
}

Citation: Smprinis, A., \& Skoumios, M. (2021). Developing the structure of junior high school students' arguments about Ohm's law. Interdisciplinary Journal of Environmental and Science Education, 17(4), e2256. https://doi.org/10.21601/ijese/11137

\begin{tabular}{ll}
\hline ARTICLE INFO & ABSTRACT \\
\hline Received: & $\begin{array}{l}\text { While students' difficulties in constructing scientific arguments have been studied, research on } \\
\text { developing the quality of students' scientific arguments through the implementation of instructional } \\
\text { interventions is limited. The present study aims to examine the effects of an instructional intervention } \\
\text { for Ohm's Law, which was designed on a teaching science as practices approach, on the development of }\end{array}$ \\
Accepted: & $\begin{array}{l}\text { the structure of students' written scientific arguments. Instructional material was constructed for } \\
\text { 24 June 2021 } \\
\text { teaching Ohm's Law and was implemented to 14-year-old students. The research data included students' } \\
\text { written answers (arguments) put down on worksheets during the instructional intervention, as well as } \\
\text { students' answers (arguments) to a questionnaire they were provided with before and after the } \\
\text { instructional intervention. Data analysis showed that the instructional intervention contributed to } \\
\text { developing the structure of students' written scientific arguments. The study concludes with a } \\
\text { discussion on the results and proposals for further research. } \\
\text { Keywords: scientific argument, structure of argument, science practices, teaching science }\end{array}$ \\
\hline
\end{tabular}

\section{INTRODUCTION}

In the traditional science teaching approach, students are meant to memorize laws and theories and implement ordered problem-solving strategies and methodologies (Sandoval, 2003), which estranges them from the appeal of exploration, standardizes science achievements, and dogmatizes scientific knowledge acquired to date (Kuhn, 1993). Under the traditional science teaching approach, only few students manage to perceive the objective image of science as a process for constructing and reviewing models and theories about the way our world works and evolves, through scientific arguments (Driver, Leach, Millar \& Scott, 1996).

The focal point of scientists' work is to construct arguments and contrast them with other scientists' arguments. In addition to scientists, it is necessary for students to be able to construct arguments (NRC, 2012). Constructing arguments is a practice necessary for all aspects of social life. It is intended that citizens understand other people's views, perceive whether they are justified, and construct arguments including claims, evidence and reasonings (McNeill \& Krajcik, 2009). The educational process should be focused on familiarizing students with the components of an argument and on developing activities that engage the students in constructing and assessing arguments. Learning involving the construction of scientific argument influences student content knowledge and can increase student understanding of content knowledge (McNeill \& Krajcik, 2009).

However, nowadays practices in the classroom provide the students with very few opportunities to construct scientific arguments (Hernandes \& Tecpan, 2018; Lemke, 1990; Driver, Newton \& Osborne, 2000). It has been suggested that students can develop the quality of their scientific arguments through properly designed instructional interventions that include activities providing the students with opportunities to express their 
conceptions and contrast with the conceptions of their peers (Driver et al., 2000; Osborne, Erduran \& Simon, 2004). Also, explicit instruction of scientific arguments and use of appropriate evidence can help students construct better scientific arguments (McNeill, 2009).

In recent years, research has highlighted the difficulties students of all educational levels find in constructing scientific arguments. Apart from gaps in understanding content, these difficulties of the students are also due to their unfamiliarity with the structure (components) of scientific arguments (Jimenez-Aleixandre, Rodriguez \& Duschl, 2000).

While there is extensive research assessing students' scientific arguments, the research that studies the impact of instructional interventions on improving the quality of scientific arguments is limited (e.g., Berland \& McNeill, 2010; Chen et al., 2016; McNeill, Lizotte, Krajcik, \& Marx, 2006; Sampson et al., 2013; Sampson \& Walker, 2012; Sandoval, 2003; Ural \& Gençoğlan, 2020; Walker \& Sampson, 2013). One of the questions that have not been fully answered in science education literature is whether quality of students' arguments changes during instructional interventions. Also, there are no studies separately investigating the structure and the content of students' scientific arguments. Furthermore, there are no studies on electric circuits investigating students' written arguments and studying the development of students' arguments during the instructional interventions. The purpose of the present study is to investigate the effects of an instructional intervention for Ohm's Law on developing the structure of students' written scientific arguments.

\section{THEORETICAL FRAMEWORK}

Components and Quality of Students' Scientific Arguments

Scientific arguments justify scientific claims or explanations through the use of reasoning and evidence (Osborne \& Patterson, 2011). McNeill and Krajcik (2012) simplified Toulmin's model of argumentation (Toulmin, 1958), in attempts to provide a framework that junior high school science students could use. According to McNeill and Krajcik (2012), students' scientific arguments consist of four components: claim, evidence, reasoning and rebuttal (Figure 1). The claim is the conclusion responding to a question, the evidence is the data supporting the claim, the reasoning links the evidence to the claim through scientific principles, and finally, the rebuttal intends to justify why any other claim would be wrong (McNeill \& Krajcik, 2012).

McNeill et al. (2006) propose a model for assessing the quality of students' scientific arguments based on two dimensions: structure and content. With regard to structure, the model at first assesses whether the argument includes all its components (claim, evidence, reasoning, and rebuttal) and then whether these components are sufficient, regardless of their content. With regard to content, the components of the argument are examined whether they are appropriate in relation to school knowledge.

\section{Teaching Science as Practices}

According to constructivist approach to learning, knowledge is not passively received by the students, but is actively constructed by them based on their prior conceptions (Forbes et al., 2014; Widolo et al., 2002). Instruction aims to negotiate and revise students' prior conceptions so that the students can construct conceptions consistent with school knowledge.

The intellectual and practical work related to processing and revising conceptions is based on students' engagement in science practices ("teaching science as practices") (NRC, 2012). The term science practices refers to the main practices in which scientists engage while studying and constructing models and theories about the natural world (NRC, 2012). The practices can be conceptualized into three groups (McNeill, Katsh-Singer \& Pelletier, 2015; McNeill et al., 2018): investigating practices (asking questions, planning and carrying out investigations, using mathematical and computational thinking), sensemaking practices (developing and using models, analyzing and interpreting data, constructing

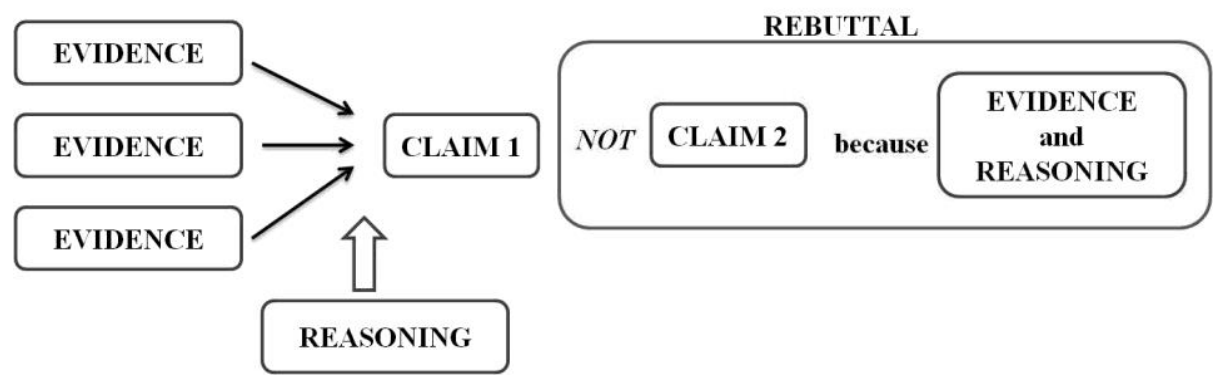

Figure 1. Framework for constructing arguments (McNeill \& Krajcik, 2012) 
explanations), and critiquing practices (engaging in argument from evidence, obtaining, evaluating, and communicating information).

These practices can push students toward deeper conceptual understanding of science ideas (Schwarz, Passmore, \& Reiser, 2017). Therefore, teachers need to engage students in the science practices in order for students to apply and explain science ideas (Krajcik, et al, 2014; Osborne \& Quinn, 2017).

\section{LITERATURE REVIEW}

Several studies have focused on assessing the quality of students' arguments. Quite often, students put forward only one claim that answers the question they are asked without evidence (Jiménez-Aleixandre et al., 2000; Kuhn, 1993; Sadler, 2004). They usually adopt the ideas of a scientist, their teacher, or one of their peers, and do not seek evidence to support their claim (Ford, 2008). They find it difficult to justify their claims by providing sufficient and appropriate evidence (Bell \& Linn, 2000; Chinn \& Brewer, 2001; Heng, Surif \& Seng, 2015; Jiménez-Aleixandre et al., 2000; Kang, Swanson \& Bauler, 2017; McNeill \& Krajcik, 2009; 2012; Moje et al., 2004; Sadler, 2004; Sandoval, 2003; Sandoval \& Millwood, 2005). They use inappropriate evidence that is either irrelevant or non-supporting (McNeill \& Krajcik, 2007) and they tend not to use all the data available to them (Sandoval \& Millwood, 2005). Several students use their personal and everyday experiences in order to support their claims (Songer, Kelcey \& Gotwals, 2009; McNeill \& Krajcik, 2009). It has been found that students find it particularly difficult to propose a reasoning connecting the evidence they provided with their claim, and, when they sometimes do so, they do not mention any scientific principles in order to support the connection between the evidence and the claim (Kelly, Drucker \& Chen, 1998; Lizotte et al., 2003; McNeill \& Krajcik, 2007, 2012; Moje et al., 2004; Sadler, 2004; Songer \& Gotwals, 2012; Zeidler, 1997). Rarely do students, but adults as well, spontaneously include rebuttals in their arguments, and, when they do so, they do not contrast with the other views using evidence and scientific principles (Kuhn, 1993; McNeill \& Krajcik, 2012; Zeidler, 1997).

It has also been recorded that when students freely express their claim, they provide no evidence at all nor do they propose a reasoning, while when they are asked to complete every component of their argument separately, they tend to construct arguments of higher quality (Gotwals, Songer \& Bullard, 2012). In their attempt to construct arguments in questions related to science issues, the students often encounter additional difficulties associated with the conceptual understanding of the phenomenon they study and the use of specialized vocabulary (Moje et al., 2004).

While students' difficulties in constructing arguments have been studied, there is limited research investigating the contribution of instructional interventions to developing the quality of students' written scientific arguments (e.g., Chen et al., 2016; González-Howard et al., 2018; Grooms et al., 2015; Klieger \& Rochsar, 2017; McNeill \& Krajcik, 2012; Sampson et al., 2013; Ural \& Gençoğlan, 2020; $\mathrm{Su}, 2020)$. The above studies have shown that the ability of the students to construct scientific arguments could be developed when the students are taught the structure of an argument and are provided with opportunities to construct and assess arguments through activities.

In case of electric circuits, students' conceptions have extensively been investigated and it was found that students use conceptions that are frequently different from school knowledge (e.g., Psillos et al., 1987; Shipstone, 1984, 1985, 1988; Shipstone et al., 1988). It was also found that instructional interventions based on the constructivist approach to learning can help students construct conceptions consistent with school knowledge (Chiu \& Lin, 2005; von Rhöneck \& Grob, 1991).

The above literature review of research shows that both students' conceptions about electric circuits and the quality of scientific arguments produced by the students have been studied. Although the construction of scientific arguments by the students has been recognized as important and studies have been carried out on dealing with students' conceptions about electric circuits, there is no research studying the contribution of instructional interventions for electric circuits to the quality of students' scientific arguments. Furthermore, the studies that have been carried out about students' arguments have studied the development of the quality (both structure and content) of arguments. There is no research separately investigating the development of the structure and the development of the content of students' scientific arguments.

\section{PURPOSE AND RESEARCH QUESTIONS}

The present study focuses on investigating the structure of students' arguments about Ohm's Law, regardless of their conceptual content. The purpose of the present study is to investigate the effects of an instructional intervention for Ohm's Law, which was designed on a teaching science as practices approach, on the development of the structure of 14-year-old students' written scientific arguments.

In particular, the present study aims to answer the following research question: What is the contribution of an instructional intervention for Ohm's Law, which 
is designed on a teaching science as practices approach, to the structure of 14-year-old junior high school students' written scientific arguments?

\section{METHODS}

Design of the Study and Sample

In the present study, the mixed method case study design, a combination of qualitative and quantitative research, was exploited and both quantitative and qualitative data was collected. "A mixed methods case study design is a type of mixed methods study in which the quantitative and qualitative data collection, results, and integration are used to provide in-depth evidence for a case(s) or develop cases for comparative analysis" (Creswell \& Plano Clarke, 2018, p.116).

This study was conducted in three phases. In the first phase, a questionnaire and the instructional material about Ohm's Law (worksheets) were developed. The questionnaire and the instructional material were implemented in three students, so that any vague points could be stressed, and then they were evaluated by two science education researchers. Remarks made by both the students and the researchers led to the appropriate corrections. The second phase included the instructional intervention in students participating in the research, while the questionnaire was implemented in them both before and after the instructional intervention. The third phase included data analysis (qualitative study of students' arguments recorded in worksheets during the instructional intervention and quantitative study of students' arguments in pre-test and post-test) and drawing conclusions.

To ensure compliance with the ethical standards and research rules, approval was granted by the Hellenic Open University's ethical committee. Also, we provided beforehand the students concerned as well as their parents with information about the aims, the content, and the process of instructional intervention, and we acquired their consent.

The research sample included 7 junior high school students (14 years old) from a Greek island (4 boys and 3 girls). All students spoke and wrote in Greek.

\section{Instructional Material about Ohm's Law}

The instructional material about Ohm's Law was designed on a teaching science as practices approach. The development of the instructional material used the learning model $5 \mathrm{E}$ by Bybee et al. (2006), which includes the following phases: engagement, exploration, explanation, elaboration, evaluation. Table 1 presents the teaching phases, the activities and the respective practices involved in them.

In the phase of engagement, students' conceptions about the relationship among electric potential difference, resistance and electric current intensity were intended to be highlighted through two problems, while the students should realize the disagreements, they had with each other. The first problem asked the students what they thought will happen to the electric current intensity if the resistance of an electric circuit is increased (Activity 1). The second problem asked the students what they thought will happen to the electric current intensity if the electric potential difference of an electric circuit is increased (Activity 2). At first, the students gave individual answers to the questions. Then they discussed their answers within their group in order to find similarities and differences and, after negotiations, they came up with the questions that should be investigated. Two questions were asked. The first was whether resistance affects electric current intensity, and the second was whether

Table 1. Teaching phases, activities and the respective science practices

\begin{tabular}{|c|c|c|}
\hline Teaching Phases & Science Practices & Activities \\
\hline Engagement & $\begin{array}{l}\text { Asking questions } \\
\text { Developing and using models } \\
\text { Engaging in argument from evidence }\end{array}$ & Activities 1 and 2 \\
\hline Exploration & $\begin{array}{l}\text { Planning and carrying out investigations } \\
\text { Analysing and interpreting data } \\
\text { Developing and using models } \\
\text { Using mathematics and computational thinking }\end{array}$ & Activities 3 and 4 \\
\hline Explanation & $\begin{array}{l}\text { Constructing explanations } \\
\text { Using mathematics and computational thinking } \\
\text { Analysing and interpreting data } \\
\text { Engaging in argument from evidence }\end{array}$ & Activities 5, 6 and 7 \\
\hline Elaboration & $\begin{array}{l}\text { Using mathematics and computational thinking } \\
\text { Constructing explanations } \\
\text { Engaging in argument from evidence }\end{array}$ & Activities 8, 9, 10 and 11 \\
\hline Evaluation & $\begin{array}{l}\text { Engaging in argument from evidence } \\
\text { Obtaining, evaluating, and communicating information }\end{array}$ & Activities 12 \\
\hline
\end{tabular}


electric potential difference affects electric current intensity.

In the phase of exploration, the students designed and carried out two scientific investigations in order to answer the questions they had asked (Activities 3 and 4). In order to design each investigation, the students were supported by a worksheet that encouraged them to ask the research question, make predictions, identify the variables involved in the problem they were studying, control the variables (by identifying the independent variable, control variables and the dependent variable), and describe the steps of the experimental process. In order to carry out each investigation, the students were provided with the equipment and materials to create the electric circuits and make the measurements. Guided by the teacher, the students made the necessary measurements and entered them into tables. With the help of the tables they drew conclusions.

The phase of explanation at first intended that the students construct scientific arguments (based on the evidence they had collected from investigations) so that they could support their own claims and refute any other claims (Activity 5). Then the teacher presented to the students the components of a scientific argument (claim, evidence, reasoning and rebuttal) and discussed with them the necessity of constructing arguments. The students were asked to identify the four components (claim, evidence, reasoning and rebuttal) of the arguments they were provided with and, with the help of the teacher, discussed the sufficiency of each and every component (Activity 6). Next, the students evaluated the arguments they had constructed with the help of self-evaluation worksheets that included rubrics. These rubrics evaluate the sufficiency levels of claims, evidence, reasonings and rebuttals of arguments (Activity 7).

In the phase of elaboration, the students were asked to implement all they had learnt (regarding Ohm's Law and the structure of an argument) in new problems. Hence, the students were asked to construct arguments with the help of a scaffolding framework that asked from the students to separately record the components of the arguments (claim, evidence, reasoning and rebuttal). The students were also asked to individually evaluate their arguments through rubrics and restate them after correcting their weaknesses (Activities 8, 9 and 10). In addition, they were also asked to compare two arguments with the same claim and different evidence or different reasonings and justify their views (Activity 11).

In the phase of evaluation, the students answered again the questions they had negotiated in the phase of engagement and compared their final with their initial arguments in order to realize the changes that took place in both their structures and their contents (Activity 12).

\section{Questionnaire}

A questionnaire was developed to assess students' ability to construct scientific arguments. The problems included in the questionnaire were designed based on the scientific argument assessment framework of Knight et al. (2013). This framework was designed using the BEAR Assessment System (BAS) (Wilson, 2005; 2009) in conjunction with elements of evidence-centered design (Mislevy et al., 2004).

The questionnaire developed included two problems (Problems 1 and 2). Each problem included a data table and a question asking from the students to use the data of the table in order to answer the question, justify their answer and justify why any other answer would be wrong.

The Problem 1 included a table with values (data) of the electric potential difference and the respective values of the electric current intensity that flows through a constant resistance. The students were asked to answer what is related to the electric current intensity that flows through a constant resistance.

The Problem 2 included a table with values of the resistance and the respective values of the electric current intensity that flows through the resistance at which a constant electric potential difference is applied. The students were asked to answer what is related to the electric current intensity flows through the resistance when a constant electric potential difference is applied.

\section{Data Collection and Analysis}

Research tools for data collection in the present study included the questionnaire and the worksheets the students used during the instructional intervention. At first (before the instructional intervention) the students completed the questionnaire (1 teaching hour). Then the instructional intervention took place based on the instructional material that had been prepared (worksheets). The instructional intervention lasted a total of 5 teaching hours. After two weeks had passed from the instructional intervention, the students were asked to answer the same questionnaire again (1 teaching hour).

Research data included students' answers (arguments), as they were recorded in the questionnaires before and after the instructional intervention as well as students' answers (arguments) given in the worksheets during the instructional intervention. 
The evaluation of the structure of students' arguments used a framework proposed by Skoumios and Hatzinikita (2014). This framework evaluates the sufficiency levels of each of the four components of a scientific argument (claim, evidence, reasoning and rebuttal) without taking their conceptual content into consideration.

Regarding the sufficiency of a claim, a scientific argument might: (a) not include a claim (Level 0), (b) include an insufficient claim (Level 1), or (c) include a sufficient claim (Level 2).

Concerning the sufficiency of evidence, an argument might: (a) not include any evidence at all (Level 0), (b) include insufficient evidence (Level 1), or (c) include sufficient evidence, that is, all the evidence supporting the claim (Level 2).

As for the sufficiency of a reasoning, an argument might: (a) not include any reasonings at all (Level 0), (b) include an insufficient reasoning, that is, a reasoning that either does not include a principle or does not connect the evidence with the claim (Level 1) or (c) include a sufficient reasoning, that is, a reasoning engaging a principle through which the evidence is connected with the claim (Level 2).

With respect to the sufficiency of a rebuttal, an argument might: (a) not include any rebuttals at all (Level 0), (b) include an insufficient rebuttal, that is, a rebuttal with insufficient evidence or an insufficient reasoning (Level 1), or (c) include a sufficient rebuttal, that is, a rebuttal engaging sufficient evidence and a sufficient reasoning (Level 2).

\section{RESULTS}

At first, results related to the development of the structure of students' arguments during the instructional intervention are presented and followed by results related to comparing the structure of students' arguments in pre-test and posttest.

The Development of the Structure of Students' Arguments during the Instructional Intervention

In the first two activities (Activities 1 and 2) of the instructional intervention, the seven students (Students A, B, C, D, E, F and G) produced arguments mostly including only claims. Particularly, Students A, $\mathrm{B}, \mathrm{D}$ and $\mathrm{E}$ produced arguments including only claims. For example, Student A in Activity 1 reported: "If the resistance is increased, the intensity of the electric current will be decreased." Regarding its structure, this argument includes a sufficient claim (Level 2) without any evidence, reasonings or rebuttals. Only a few arguments included evidence, reasonings or rebuttals in addition to claims. However, the evidence, the reasonings and the rebuttals were insufficient. Such arguments were produced by
Students F and G. For example, Student F in Activity 1 reported: "If the resistance is increased, the intensity will be decreased because resistance is inversely proportional to intensity." Regarding its structure, this argument includes a sufficient claim (Level 2), an insufficient reasoning (Level 1) and no evidence or rebuttals at all (Level 0 ).

In Activity 5, although the students had obtained measurements of the resistance and the intensity of the electric current in a circuit with constant electric potential difference, they produced arguments that included either only claims or claims and insufficient evidence or an insufficient reasoning. Such arguments did not include any rebuttals at all. For example, Student A reported: "The intensity of the electric current changes if we increase the resistance, that is, the more the resistance is increased, the more the intensity of the electric current is decreased."This argument includes only a claim, which is considered sufficient (Level 2). However, no evidence, reasonings or rebuttals are included. In the same activity, Student E reported: "The more we increase the resistance, the more the intensity of the electric current is decreased. Resistance and electric current intensity are inversely proportional to each other on condition that we have the same source." This argument includes a claim considered sufficient (Level 2), does not include any evidence (Level 0) or rebuttals (Level 0 ) at all, but includes a reasoning considered insufficient since the evidence cannot be connected with the claim through this reasoning (Level 1).

In Activities 8, 9 and 10, it was found that the structure of the arguments produced by the students with regard to the sufficiency of evidence, reasonings and rebuttals had improved. Particularly, Students E, $\mathrm{F}$ and $\mathrm{G}$ produced arguments that included sufficient claims as well as sufficient evidence, reasonings and rebuttals. For example, student F reported: "If we increase the resistance while keeping the electric potential difference constant, the intensity of the electric current will be decreased. The values of the table above show that when the resistance is $10 \Omega$, the intensity of the electric current is $1.2 \mathrm{~A}$; when we double the resistance, the intensity of the electric current is halved; when we triple the resistance, the intensity is three times down. As seen from the above values and according to Ohm's Law, the values I and $R$ are inversely proportional to each other; therefore, when we increase resistance, the intensity of the electric current is decreased. Any other claim about the relationship between the two values is wrong because the values of the table above show that the values of $R$ and I are constant, which means that they are inversely proportional to each other according to Ohm's Law." This argument includes a sufficient 
claim (Level 2), insufficient evidence (Level 1), a sufficient reasoning (Level 2) and a sufficient rebuttal (Level 2). Students A, C and E produced arguments that included sufficient claims with insufficient evidence or reasonings and insufficient rebuttals. For example, Student A reported: "The intensity of the electric current decreases while the resistance is increased. The measurements of the table confirm that I decreases while R is increased. According to the measurements and Ohm's Law when the electric potential difference is constant, intensity I and resistance $R$ are inversely proportional variables to each other and, therefore, when one variable is decreased, the other increases. I think that my claim is correct because the values of the table confirm my reasoning." This argument includes a sufficient claim (Level 2), insufficient evidence (Level 1) and a sufficient reasoning (Level 2), but it does not include a rebuttal (Level 0). However, Student B continued including only claims in his arguments. For example, he reported: "I think that the lower the electrical resistance, the higher the electric current intensity. I think that my argument is correct because we have done it with my schoolmates."

After studying students' arguments given in their worksheets, it was found that most students arguments were improved with regard to the sufficiency of their components during the instructional intervention.

\section{The Structure of Students' Arguments in Pre-test} and Post-test

The Table 2 presents frequencies and percentages referring to the sufficiency of the components of students' arguments in pre-test and post-test.

It becomes clear that all pre-test and post-test students' arguments include claims, most of which are considered sufficient. However, an improvement in the sufficiency of the claims of students' arguments was found in post-test as compared to pre-test. Furthermore, most students' arguments in pre-test did not include any evidence, while when evidence was included, it was considered insufficient. There were no arguments with sufficient evidence. On the other hand, almost all arguments in post-test included evidence, though most of it was sufficient. In addition, most arguments in pre-test did not include any reasonings. By contrast, most arguments in posttest included reasonings. Half of these reasonings were sufficient and the rest of them insufficient. Finally, almost none of the arguments in pre-test included a rebuttal. However, more than half of the arguments in post-test included sufficient rebuttals. As a result, as compared to their pre-test arguments, students' arguments improved in post-test mainly with regard to the sufficiency of evidence, reasonings and rebuttals.

\section{DISCUSSION AND CONCLUSIONS}

The present study aimed to investigate the effects of an instructional intervention for Ohm's Law, which was designed on a teaching science as practices approach, on the development of the structure of junior high school students' (14 years old) written scientific arguments. The written arguments produced by the students in their worksheets during the instructional intervention as well as students' answers to the questions of the questionnaires before and after the instructional intervention were analyzed.

Before the instructional intervention (as concluded from the analysis of students' arguments in pre-test) as well as in the first activities of the instructional intervention (as concluded from the

Table 2. Sufficiency levels of claims, evidence and reasoning of written arguments of students in pre-test and post-test: Frequencies and percentages

\begin{tabular}{|c|c|c|c|c|c|}
\hline \multirow[t]{2}{*}{ Components } & \multirow[t]{2}{*}{ Levels } & \multicolumn{2}{|c|}{ Pre-test } & \multicolumn{2}{|c|}{ Post-test } \\
\hline & & $f$ & $\%$ & $f$ & $\%$ \\
\hline \multirow[t]{3}{*}{ Claim } & Level 0 & 0 & 0 & 0 & 0 \\
\hline & Level 1 & 5 & 35.7 & 2 & 14.3 \\
\hline & Level 2 & 9 & 64.3 & 12 & 85.7 \\
\hline \multirow[t]{3}{*}{ Evidence } & Level 0 & 10 & 71.4 & 1 & 7.1 \\
\hline & Level 1 & 4 & 28.6 & 9 & 64.3 \\
\hline & Level 2 & 0 & 0 & 4 & 28.6 \\
\hline \multirow[t]{3}{*}{ Reasoning } & Level 0 & 11 & 78.6 & 4 & 28.6 \\
\hline & Level 1 & 3 & 21.4 & 5 & 35.7 \\
\hline & Level 2 & 0 & 0 & 5 & 35.7 \\
\hline \multirow[t]{3}{*}{ Rebuttal } & Level 0 & 13 & 92.9 & 6 & 42.9 \\
\hline & Level 1 & 1 & 7.1 & 0 & 0 \\
\hline & Level 2 & 0 & 0 & 8 & 57.1 \\
\hline
\end{tabular}


analysis of students' arguments given in their worksheets), the structure of students' written arguments was insufficient. In particular, the arguments included claims. Rarely did they include any evidence, reasonings or rebuttals. In the few cases where the above components were included, they were insufficient. These results are in line with the results of other research studies that have realized the insufficiency of students' arguments (Jimenez-Aleixandre et al., 2000; McNeill \& Krajcik, 2007, 2012; Moje et al., 2004; Osborne et al., 2013). The low quality of students' arguments about their structure could be attributed to the fact that rarely are the students asked in the classroom to construct arguments in order to support a claim (with evidence and reasonings) and refute another claim or to dispute their schoolmates' claims (Hernandes \& Tecpan, 2018; Lemke, 1990; Driver et al., 2000). On top of that, the students are rarely taught the components (structure) of a scientific argument (Driver et al., 2000).

However, during the instructional intervention and particularly in its last activities (as shown after analyzing students' arguments recorded in their worksheets), the structure of students' written arguments improved. Apart from claims, students' arguments also included (whether insufficient or sufficient) evidence, reasonings and rebuttals. It was also found (after analyzing students' arguments in pre-test and post-test) that the structure of students' arguments in post-test had improved as compared to the structure of their arguments in pre-test. This means that the instructional intervention contributed to improving the structure of students' scientific arguments.

The development of the structure of students' scientific arguments could be attributed to activities of the instructional material. More specifically, in Activity 6, the students were introduced to the structure of a scientific argument (claim, evidence, reasoning, rebuttal), and the necessity of each component was explained to them. They were also provided with opportunities to become familiar with locating the components of arguments in texts they studied and examine (under the guidance of the teacher) their sufficiency. As demonstrated by research data, such processes could help students construct arguments (Chen et al., 2016; McNeill \& Krajcik, 2008; 2012; Zohar \& Nemet, 2002). Moreover, there were activities (e.g., Activities 8, 9 and 10) that proposed to the students supporting frameworks that could be used by them for constructing arguments or restating their arguments (frameworks encouraging students to separately record a claim, the evidence supporting the claim, a reasoning and a rebuttal). Research that has been conducted has shown that when the students use these frameworks, they can construct arguments with improved structure (Berland \& McNeill, 2010; Klieger \& Rochsar, 2017; Lee, Cite, \& Hanuscin, 2014). In addition, Activities 8, 9 and 10 provided the students with opportunities to evaluate by themselves the arguments they produced (selfevaluation) with the help of rubrics and then to record a second version of their arguments once again. Research has shown that these processes can improve the structure of students' arguments (McNeill \& Krajcik, 2008; 2012). Indeed, in Activities 8, 9 and 10 there was an improvement in the structure of arguments produced by the students with regard to the sufficiency of evidence, reasonings and rebuttals. It becomes obvious that explicitly teaching the structure of a scientific argument, providing the students with supporting frameworks for recording the components of an argument, and individually evaluating arguments (using rubrics) are teaching strategies for improving the structure of arguments constructed by the students. However, it should also be noted that the above are assumptions and further research is required so that they can be verified.

The results of the present study are subject to restrictions related to the small sample. The research was conducted with the participation of seven students of a junior high school class of a remote Greek island. In addition, because the research focused on only one science subject (Ohm's Law), this was an additional restriction. Consequently, the results cannot generally be applied. Also, this research studied only written rather than oral arguments of students.

Despite the above restrictions, the present study contributes to the research on improving the structure of junior high school students' written scientific arguments, through instructional interventions. Research conducted to date on the effects of instructional interventions on the quality of students' scientific arguments has been limited. There was no research studying the contribution of instructional interventions to the quality of students' arguments for electrical circuits. The present study showed that the structure of students' written arguments can be improved through an instructional intervention for Ohm's Law based on a teaching science as practices approach. Furthermore, the research conducted to date was focused either on the whole quality (structure and content) or only on the content of scientific arguments. There was no research focusing on the impact the instructional interventions had exclusively on the structure of students' scientific arguments. The present study "sheds light" on this direction. This study further 
supports existing science education literature across grade levels and science domains that explicit instruction in scientific argument improves the structure of students' written arguments for Ohm's Law. Additionally, the study demonstrated that the structure of written scientific arguments seems to improve with scaffolded practice during the instructional intervention.

The present study showed that improving the structure of 14-year-old students' arguments through the designed instructional intervention for $\mathrm{Ohm}$ 's Law is possible. However, further research is required for verifying the effectiveness of this instructional intervention in an adequate sample of students. Furthermore, this study focused on the structure of students' arguments. Further research is required for separately studying the structure, the content and the linguistic characteristics (vocabulary, syntactic conventions) of students' arguments. In addition, the present study focused on students' written scientific arguments. It would be of research interest to study the impact of the instructional intervention for Ohm's Law on students' oral arguments as well as to investigate the differentiations between students' abilities to construct oral arguments and their abilities to construct written arguments, an issue with no research data at all.

\section{REFERENCES}

Bell, P., \& Linn, M. C. (2000). Scientific arguments as learning artifacts: Designing for learning from the Web with KIE. International Journal of Science Education, 22(8), 797-817. https://doi.org/10.1080/095006900412284

Berland, L., \& McNeill, K. (2010). A learning progression for scientific argumentation: Understanding student work and designing supportive instructional contexts. Science Education, 94(5), 765-793.

https://doi.org/10.1002/sce.20402

Bybee, R., Taylor, J., Gardner, A., Van Scotter, P., Powell, J. C., Westbrook, A., \& Landes, N. (2006). The BSCS $5 E$ instructional model: Origins and effectiveness. Colorado Springs.

Chen, H.-T., Wang, H.-H., Lu, Y.-Y., Lin, H., \& Hong, Z.-R. (2016). Using a modified argument-driven inquiry to promote elementary school students' engagement in learning science and argumentation. International Journal of Science Education, 38(2), 170-191.

https://doi.org/10.1080/09500693.2015.1134849

Chinn, C. A. \& Brewer, W. F. (2001). Models of data: A theory of how people evaluate data. Cognition and Instruction, 19(3), 323-393. https://10.1207/S1532690XCI1903_3
Chiu, M.-H. \& Lin, J.-W. (2005). Promoting fourth graders' conceptual change of their understanding of electric current via multiple analogies. Journal of Research in Science Teaching, 42(4), 429-464. https://doi.org/10.1002/tea.20062

Creswell, J. W., \& Plano Clark, V. (2018). Designing and conducting mixed methods research (3rd ed.). Thousand Oaks, CA: SAGE.

Driver, R., Leach, J., Millar, R., \& Scott, P. (1996). Young people's images of science. Buckingham, England: Open University Press.

Driver, R., Newton, D., \& Osborne, J. (2000). Establishing the norms of scientific argumentation in classrooms. Science Education, 84(3), 287-312. https://doi.org/10.1002/(SICI)1098237X(200005)84:3<287::AID-SCE1>3.0.C0;2-A

Forbes, C., Lange, K., Möller, K., Biggers, M., Laux, M., \& Zangori, L. (2014). Explanation construction in fourth-grade classrooms in Germany and the USA: A cross-national comparative video study.

International Journal of Science Education, 36(14), 2367-2390.

https://doi.org/10.1080/09500693.2014.923950

Ford, M. (2008). Disciplinary authority and accountability in scientific practice and learning. Science Education, 92(3), 404-423. https://doi.org/10.1002/sce.20263

González-Howard, M., Marco-Bujosa, L., McNeill, K. L., Goss, M. \& Loper, S. (2018). The argumentation toolkit: A resource for integrating argumentation into your science classroom. Science Scope, 42(3), 74-78.

Gotwals, A. W., Songer, N. B., \& Bullard, L. (2012). Assessing students' progressing abilities to construct scientific explanations. In A. C. Alonzo \& A. W. Gotwals (Eds.), Learning progressions in science: Current challenges and future directions (pp. 183-210). The Netherlands: Sense Publishing.

Grooms, J., Enderle, P., \& Sampson, V. (2015). Coordinating scientific argumentation and the next generation science standards through argument driven inquiry. Science Educator, 24(1), 45-50.

Heng, L. L., Surif, J., \& Seng, C. H. (2015). Malaysian students' scientific argumentation: Do groups perform better than individuals? International Journal of Science Education, 37(3), 505-528. https://doi.org/10.1080/09500693.2014.995147

Hernandez, C., \& Tecpan, S. (2018). Correct answers with wrong justifications? Analysis of explanations in classical mechanics with FCI test. Journal of Physics: Conference Series, 1043(1), 012056.

Jimenez-Aleixandre, M. P., Rodriguez, A. B., \& Duschl, R. A. (2000). "Doing the lesson" or" doing science": Argument in high school genetics. Science Education, 84(6), 757-792. https://doi.org/10.1002/1098237X(200011)84:6<757::AID-SCE5>3.0.CO;2-F

Kang, E.J.S., Swanson, L.H., \& Bauler, C.V. (2017). 'Explicame': Examining emergent bilinguals' ability 
to construct arguments and explanations during a unit on plate tectonics. Electronic Journal of Science Education, 21(6), 12-45.

Kelly, G. J., Drucker, S., \& Chen, C. (1998). Students' reasoning about electricity: Combining performance assessments with argumentation analysis. International Journal of Science Education, 20(7), 849-871. https://doi.org/10.1080/0950069980200707

Klieger, A., \& Rochsar, A. (2017). Impartation of argumentation skills: Impact of scaffolds on the quality of arguments. Journal of Advances in Education Research, 2(3), 183-190. https://doi.org/10.22606/jaer.2017.23006

Knight, A. M., McNeill, K. L., Corrigan, S., \& Barber, J. (2013, April). Student assessments for reading and writing scientific arguments. Paper presented at the annual meeting of the American Educational Research Association, San Francisco.

Krajcik, J., Codere, S., Dahsah, C., Bayer, R. \& Mun, K. (2014). Planning instruction to meet the intent of the Next Generation Science Standards. Journal of Science Teacher Education, 25(2), 157-175. https://doi.org/10.1007/s10972-014-9383-2

Kuhn, D. (1993). Science as argument: Implications for teaching and learning scientific thinking. Science Education, 77(3), 319-337.

https://doi.org/10.1002/sce.3730770306

Lee, E. J., Cite, S., \& Hanuscin, D. (2014). Taking the "mystery" out of argumentation: A traditional mystery-powders lesson is modified to emphasize argumentation. Science and Children, 52(1), 46-52.

Lemke, J. (1990). Talking science: Language, learning, and values. Norwood, New Jersey: Ablex Publishing Corporation.

Lizotte, D. J., Harris, C. J., McNeill, K. L., Marx, R. W., \& Krajcik, J. (2003, April). Usable assessments aligned with curriculum materials: Measuring explanation as a scientific way of knowing. In annual meeting of the American Educational Research Association, Chicago, IL.

McNeill, K. L. (2009). Teachers' use of curriculum to support students in writing scientific arguments to explain phenomena. Science Education, 93(2), 233268. https://doi.org/10.1002/sce.20294

McNeill, K. L., Lizotte, D. J., Krajcik, J., \& Marx, R. W. (2006). Supporting students' construction of scientific explanations by fading scaffolds in instructional materials. Journal of the Learning Sciences, 15(2), 153-191. https://doi.org/10.1207/s15327809jls1502_1

McNeill K. L., \& Krajcik J. (2007). Middle school students' use of appropriate and inappropriate evidence in writing scientific explanations. In M. Lovett \& P. Shah (Eds.), Thinking with Data: The proceedings of the 33rd Carnegie Symposium on Cognition (pp. 233-265). Lawrence Erlbaum Associates, Inc.
McNeill, K. L. \& Krajcik, J. (2008). Scientific explanations: Characterizing and evaluating the effects of teachers' instructional practices on student learning. Journal of Research in Science Teaching, 45(1), 53-78.

https://doi.org/10.1002/tea.20201

McNeill, K. L., \& Krajcik, J. (2009). Synergy between teacher practices and curricular scaffolds to support students in using domain-specific and domaingeneral knowledge in writing arguments to explain phenomena. Journal of Learning Sciences, 18(3), 416-460.

https://doi.org/10.1080/10508400903013488

McNeill, K. L., \& Krajcik, J. (2012). Supporting grade 5-8 students in constructing explanations in science: The claim, evidence and reasoning framework for talk and writing. New York. NY: Pearson Allyn \& Bacon.

McNeill, K. L., Katsh-Singer, R. \& Pelletier, P. (2015). Assessing science practices - Moving your class along a continuum. Science Scope, 39(4), 21-28.

McNeill, K.L., Lowenhaupt, R., \& Katsh-Singer, R. (2018). Instructional leadership and the implementation of the NGSS: Principals' understandings of science practices. Science Education, 102(3), 452-473.

https://doi.org/10.1002/sce.21336

Mislevy, R. J., Almond, R. G., \& Lukas, J. F. (2004). A brief introduction to Evidence-Centered Design. CSE Technical Report 632, The National Center for Research on Evaluation, Standards, and Student Testing (CRESST), Center for the Study of Evaluation (CSE). LA, CA: University of California, Los Angeles.

Moje, E. B., Peek-Brown, D., Sutherland, L. M., Marx, R. W., Blumenfeld, P., \& Krajcik, J. (2004). Explaining explanations: Developing scientific literacy in middle-school project-based science reforms. In D. Strickland \& D. E. Alvermann (Eds.), Bridging the gap: improving literacy learning for preadolescent and adolescent learners in grades (pp. 4-12). New York: Carnegie Corporation.

National Research Council (NRC). (2012). A framework for K-12 science education: Practices, crosscutting concepts and core ideas. Washington, DC: National Academy Press. https://doi.org/10.17226/13165

Osborne, J., Erduran, S., \& Simon, S. (2004). Enhancing the quality of argumentation in school science. Journal of Research in Science Teaching, 41(10), 994-1020. https://doi.org/10.1002/tea.20035

Osborne, J., \& Quinn, H. (2017). The framework, the NGSS, and the practices of science. In C.V. Schwarz, C. Passmore, \& B. Reiser (Eds.), Helping students make sense of the world using next generation science and engineering practices (pp. 59-83). Arlington, VA: NSTA Press.

Osborne, J. F., \& Patterson, A. (2011). Scientific argument and explanation: a necessary distinction? 
Science Education, 95, 627-638.

https://doi.org/10.1002/sce.20438

Osborne, J., Simon, S., Christodoulou, A., Howell-

Richardson, C., \& Richardson, K. (2013). Learning to argue: A study of four schools and their attempt to develop the use of argumentation as a common instructional practice and its impact on students. Journal of Research in Science Teaching, 50(3), 315-347. https://doi.org/10.1002/tea.21073

Psillos, D., Koumaras, P., \& Valassiades, O. (1987). Pupils' representations of electric current before, during and after instruction on DC circuits.

Research in Science and Technological Education, 5(2), 185-199.

https://doi.org/10.1080/0263514870050209

Sadler, T. D. (2004). Informal reasoning regarding socioscientific issues: A critical review of research. Journal of Research in Science Teaching, 41(5), 513-536. https://doi.org/10.1002/tea.20009

Sampson, V., \& Walker, J. P. (2012). Argument-driven inquiry as a way to help undergraduate students write to learn by learning to write in chemistry. International Journal of Science Education, 34(10), 1443-1485.

https://doi.org/10.1080/09500693.2012.667581

Sampson, V., Enderle, P., Grooms, J., \& Witte, S. (2013). Writing to learn by learning to write during the school science laboratory: Helping middle and high school students develop argumentative writing skills as they learn core ideas. Science Education, 97(5), 643-670.

https://doi.org/10.1002/sce.21069

Sandoval, W.A. (2003). Conceptual and epistemic aspects of students' scientific explanations. Journal of the Learning Science, 12(1), 5-51.

https://doi.org/10.1207/S15327809JLS1201_2

Sandoval, W. A., \& Millwood, K. A. (2005). The quality of students' use of evidence in written scientific explanations. Cognition and Instruction, 23(1), 2355. https://doi.org/10.1207/s1532690xci2301_2

Schwarz, C., Passmore, C., \& Reiser, B. J. (Eds.). (2017). Helping students make sense of the world using Next Generation Science and Engineering Practices. NSTA Press.

Shipstone, D. M. (1984). A study of children's understanding of electricity in simple D.C. circuits. European Journal of Science Education, 6(2), 185198. https://doi.org/10.1080/0140528840060208

Shipstone, D. (1985). On children's use of conceptual models in reasoning about current electricity. In R. Duit, W. Jung \& C. von Rhöneck (Eds.), Aspects of understanding electricity. Proceedings of an international workshop, 1984 (pp. 73-82). Kiel, Germany: Schmidt \& Klaunig.

Shipstone, D. (1988). Pupils' understanding of simple electrical circuits. Physics Education, 23, 92-96. https://doi.org/10.1088/0031-9120/23/2/004

Shipstone, D. M., Rhöneck, C. V., Karrqvist, C., Dupin, J., Johsua, S., \& Licht, P. (1988). A study of student' understanding of electricity. International Journal of Science Education, 10(3), 303-316.

https://doi.org/10.1080/0950069880100306

Skoumios, M. \& Hatzinikita, V. (2014). Assessing students' science written arguments. Natural Sciences in Education, 3, 9-19. [in Greek]

Songer, N. B., \& Gotwals, A. W. (2012). Guiding explanation construction by children at the entry points of learning progressions. Journal of Research in Science Teaching, 49(2), 141-165. https://doi.org/10.1002/tea.20454

Songer, N. B., Kelcey, B., \& Gotwals, A. W. (2009). How and when does complex reasoning occur? Empirically driven development of a learning progression focused on complex reasoning about biodiversity. Journal of Research in Science Teaching, 46(6), 610-631. https://doi.org/10.1002/tea.20313

Su, K-D. (2020). An argumentation-based study with concept mapping approach in identifying students' scientific performance skills. Interdisciplinary Journal of Environmental and Science Education, 16(4), e2222. https://doi.org/10.29333/ijese/8544

Toulmin, S. (1958). The use of arguments. Weinheim, Germany, Beltz.

Ural, E., \& Gençoğlan, D. M. (2020). The effect of argumentation-based science teaching approach on 8th graders' learning in the subject of acids-bases, their attitudes towards science class and scientific process skills. Interdisciplinary Journal of Environmental and Science Education, 16(1), e02207. https://doi.org/10.29333/ijese/6369 von Rhöneck, C., \& Grob, K. (1991). Psychological aspects of learning about basic electricity in rural and urban classes. International Journal of Science Education, 13, 87-95.

https://doi.org/10.1080/0950069910130108

Walker, J. P., \& Sampson, V. (2013). Learning to argue and arguing to learn: Argument-driven inquiry as a way to help undergraduate chemistry students learn how to construct arguments and engage in argumentation during a laboratory course. Journal of Research in Science Teaching, 50(5), 561-596. https://doi.org/10.1002/tea.21082

Widodo, A., Duit, R,, \& Müller, C. (2002). Constructivist views of teaching and learning in practice:

Teachers' views and classroom behavior. In: Annual Meeting of the National Association for Research in Science Teaching, New Orleans, US, 7-10 April 2002. New Orleans: NARST Publications, $1-18$.

Wilson, M. (2005). Constructing measures: An item response modeling approach. Mahwah, $\mathrm{NJ}$ : Lawrence Erlbaum Associates.

Wilson, M. (2009). Measuring progressions: Assessment structures underlying a learning progression. Journal of Research in Science Teaching, 46(6), 716-730. https://doi.org/10.1002/tea.20318 
Zeidler, D. L. (1997). The central role of fallacious thinking in science education. Science Education, 81(4), 483-496.

https://doi.org/10.1002/(SICI)1098237X(199707)81:4<483::AID-SCE7>3.0.C0;2-8

Zohar, A., \& Nemet, F. (2002). Fostering students' knowledge and argumentation skills through dilemmas in human genetics. Journal of Research in Science Teaching, 39(1), 35-62.

https://doi.org/10.1002/tea.10008 